\title{
Work
}

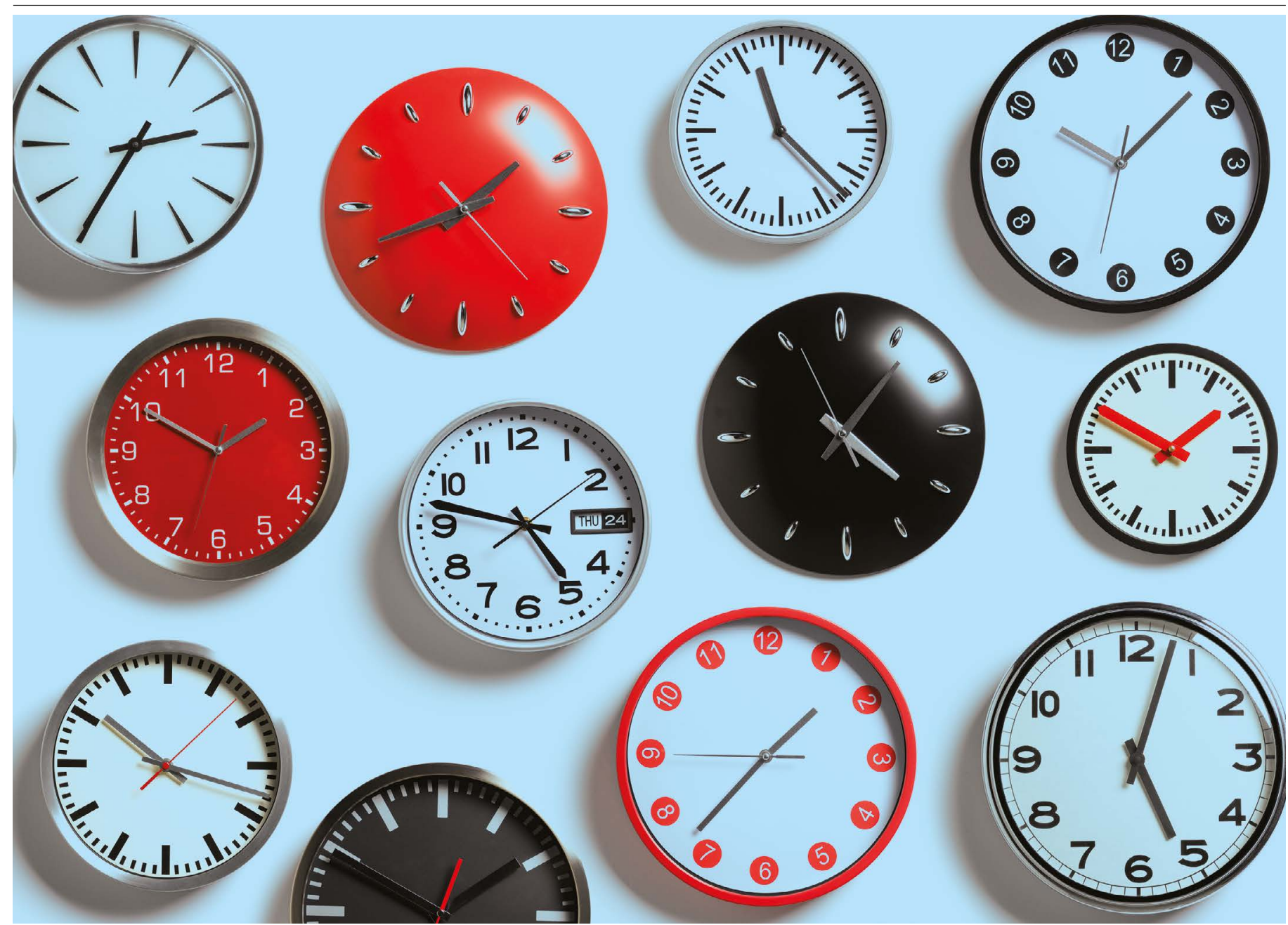

During the COVID-19 pandemic, stress and the burden of household tasks did not fall equally on all scientists.

\section{SCIENCENEEDSANEWREWARD ANDRECOGNITIONSYSTEM}

\section{Researchers with carer roles have struggled during the pandemic, amplifying existing inequalities. By Edyta Swider-Cios and colleagues}

T he chance of 'success' in an academic science career, which has historically been defined as obtaining a permanent position, is low ${ }^{1,2}$. Because of this, early-career researchers, including PhD students, postdocs and junior faculty members, are vulnerable to extra stresses ${ }^{3-5}$.

From June to October 2020, we surveyed 151 such researchers in different fields and from multiple countries in Europe to better understand how they were affected by pandemic-related lockdowns and associated relief efforts - such as extensions on grant or scholarship reporting and eligibility, and budget-neutral project extensions.

Not surprisingly, we found that the pandemic has amplified existing discrepancies between these researchers, especially between those with and without carer responsibilities. Some funders and academic institutions have provided deadline extensions or extended contracts. But these efforts might offer advantages only to certain groups, owing to their eligibility conditions and how well publicized they are. It is alarming that these measures might increase existing inequalities in academia as the pandemic continues into a second year and a return to normality remains unpredictable.

Of our survey respondents, $68 \%$ were women and $31 \%$ were men ( $1 \%$ had a different 


\section{Work/Careers}

gender identity or did not disclose it). Roughly half the respondents are members of a Young Academy, such as a National Young Academy or the Young Academy of Europe, which suggests that they are successful in their field and have a leadership role. Given the relatively small number of participants and the complexity of this survey, we can draw only qualitative conclusions. Respondents who have been negatively affected were more likely to respond than were others, and one-third of our respondents are from Hungary, which could bias our results. Our survey, which was financially supported by the CALIPER project, produced three key findings, and our data are available online (go.nature.com/3iuh). Freetext responses further illustrated the conclusions we've drawn (see 'Free-text responses').

\section{Balancing work and care is hard}

We found that researchers with children under the age of 10 struggled the most to balance home-schooling and professional work. Our participants did not have other significant carer responsibilities beyond those for their own children, although we presume that those who provide care for an older person or dependent family member would experience similar difficulties. The absence of inperson school or day care (see 'Lost safety net') resulted in these respondents spending up to 8 extra hours daily on childcare and household activities (see 'Growing responsibilities').

\section{Gender bias persists}

Even before the pandemic, the average time spent on household activities differed between researchers with and without kids (see 'Growing responsibilities'). Most scientist-parents spent 5-6 hours per day on household activities, whereas researchers without kids spent less than 3-4 hours. The pandemic further exacerbated these differences, especially for women with children. Our results indicate that women experienced more stress than men did during the lockdown (see 'Stress factor'). There were even differences between genders in the amount of hours spent asleep (see 'Work-life imbalance'). Other articles have also outlined how the pandemic has hit academic scientistmums harder than their male or non-parent counterparts $^{6,7}$.

\section{Some people benefited}

Those who did not suffer from restricted laboratory access or non-ideal working conditions at home might have experienced an advantage from working remotely. Many reported having fewer meetings, administrative tasks or disturbances, and noted that they were able to quietly focus on their work - an accomplishment that is almost impossible for scientist-parents with young children at home, especially before the kids' bedtime.

\section{LOCKDOWNEFFECTS}

The pandemic has amplified existing discrepancies among researchers, especially between those with and without carer responsibilities. Female scientists also reported far more domestic obligations and higher stress levels than did male scientists; more female scientists than their male counterparts also worked longer hours and got less sleep.

\section{Lost safety net}

The pandemic closed the doors of many day-care centres and schools, an important resource for almost all respondents with children in pre-pandemic times. The percentage of children who spent no time at a day-care provider or in a school building during the pandemic jumped from $5 \%$ to $70 \%$.

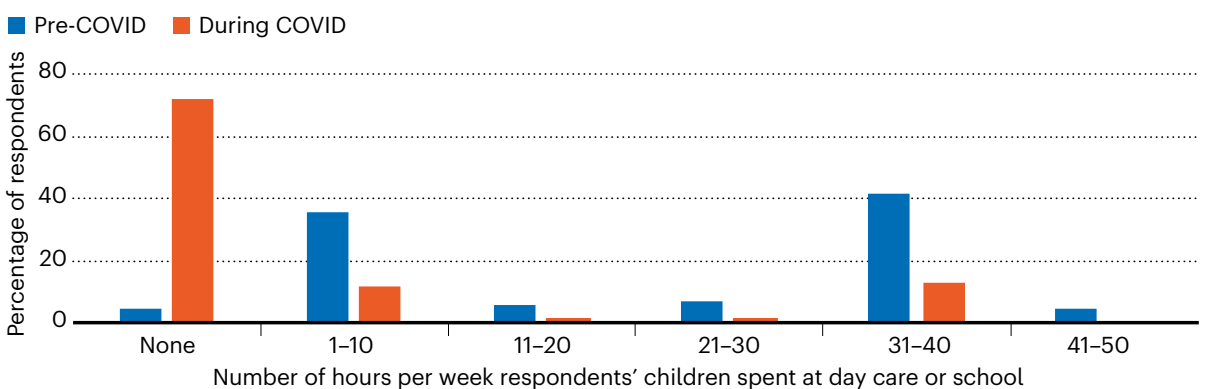

\section{Growing responsibilities}

Women with children were already devoting many hours to household tasks before the pandemic. During the pandemic, they took on an even greater share of the responsibilities. A majority reported spending at least 9 hours per day on domestic duties.

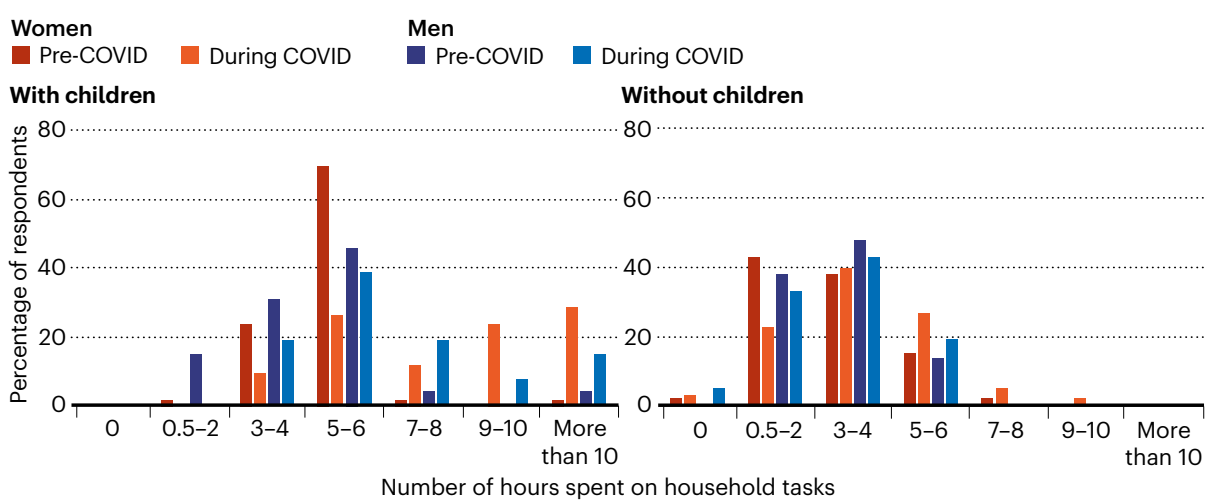

Stress factor

Women and men were equally likely to report feeling very stressed or burnt out. They were also equally likely to report not being stressed at all. But differences become apparent between those two extremes: women were more likely to report feeling 'moderately' stressed, whereas men were more likely to report being 'a little bit' stressed.

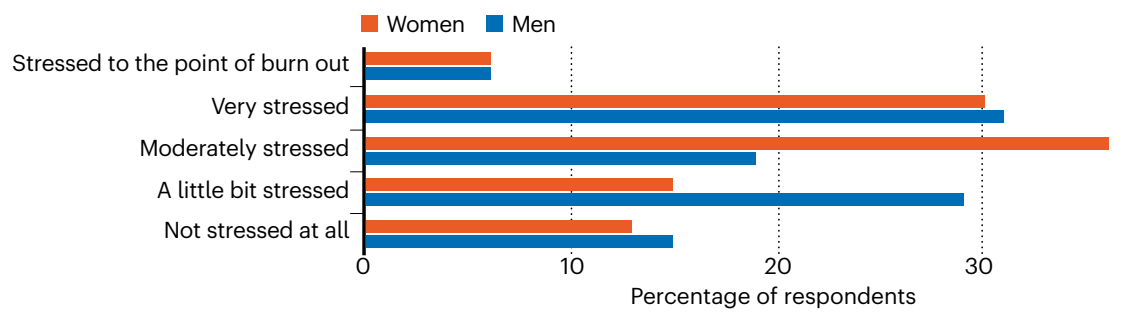

\section{Work-life imbalance}

The pandemic affected mothers and fathers differently. The proportion of women getting at least 7 hours of sleep each day dropped, as did the proportion who worked more than 10 hours per day. Slightly more men, conversely, got at least 7 hours of sleep during the pandemic.

\section{Women
$\square$ Pre-COVID $\square$ During COVID $\quad \square$ Pre-COVID $\square$ During COVID}

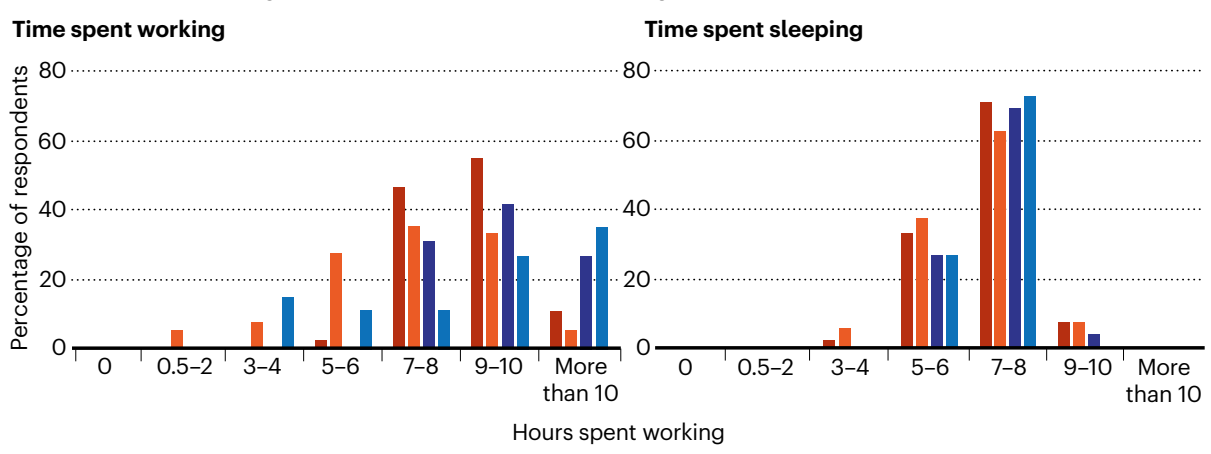


However, those with no carer obligations often had to take on work responsibilities - particularly teaching and administrative work, but also experimental work, instrument maintenance and activities that required an in-person presence at the workplace, such as looking after cell, bacterial or fungal cultures, experimental animals or plants - from others who did have such obligations. These scientists might also have experienced a decrease in actual research time, as well as increased stress levels because of their higher workloads and feelings of isolation (and possibly increased exposure risk to SARS-CoV-2 when they had to go into their workplace).

\section{Interventions}

Funding agencies' mitigation measures have varied. Some have given extensions to everyone by, for example, extending eligibility windows for a year (for example, a grant that allowed researchers to apply within three years of receiving their doctoral degree would be extended to four years), or extending existing projects, often at no extra cost. This is a strong start to helping researchers. Yet simple extensions for all are not ideal, because they could penalize those who cannot work from home effectively, and could give a boost to those who can do so. This disparity could worsen existing inequalities in the research enterprise, and could prompt scientists from disadvantaged groups to reconsider their career options and think about leaving academia.

On the bright side, most academic institutions have normalized working from home. This allows for far greater flexibility, which in the long run is an advantage for scientists with carer responsibilities, and in general can improve work-life balance for everyone. Similarly, although online webinars and conferences have their own limitations - especially in terms of informal, in-person networking - they are more accessible than are their on-site counterparts to scientists who have fewer financial resources or those with less mobility, and, as such, can significantly increase the diversity of attendees. We hope that issues such as the unequal carer responsibilities, evaluation criteria that make it more difficult for women and minority groups to advance, and a lack of diversity and gender balance in scientific panels, and among invited speakers and those in senior roles in academia, will continue to receive attention ${ }^{8}$ after the pandemic ends.

The consequences of the pandemic, and the difficulties that it has caused for many scientists, call for accelerating the development of new ways to recognize and reward academic researchers. To mitigate the problems we identify here, which have also been brought up by others (go.nature.com/3hgs), we suggest that scientists should be appraised on their efforts and progress in light of their

\section{Free-text responses}

\section{Free-text responses illustrate the struggles some respondents face in terms of childcare during the pandemic.}

"A number of leadership roles have been offered and awarded in my department during the lockdown, which I and others with similar (short-term) childcare difficulties were simply not in a position to apply for."

"I feel terribly disadvantaged. My children are 3 and 5 , and require permanent attention. My husband is a key worker, I get a few hours a day [for work], essentially for teaching, and no progress on my research."

"The combination of home-schooling and a kindergarten-age child at home was extremely burdensome. No full-time work possible during that time."

\section{Free-text responses also highlighted respondents' experience of gender bias.}

"My male colleagues all seem to manage to pursue their research brilliantly, and that creates a terribly unfair bias for the next funding application or the professor promotion."

"Even in households with two parents of different genders, it's quite remarkable how much more childcare fell to the woman

personal circumstances, and funders should move towards evaluating narrative CVs, instead of using assessments focused only on impact factors and other quantitative performance indicators.

We already know that academia treats those in the sector unequally, penalizing carers, women and those from minority ethnic groups $^{9-12}$. In our view, intervention is necessary, and existing solutions are welcome, but are insufficient on their own. The degree of support that a researcher receives - when they receive it at all - needs to be more nuanced than simple extensions for everyone. It is necessary to gauge the impact that the lockdown has had on an individual and their work before awarding an extension. This would require a careful and personalized career-evaluation procedure.

We recognize that this creates more work for reviewers, evaluation committees and others, but we do not want the pandemic's effects to fortify the proverbial glass ceiling.

Edyta Swider-Cios is a researcher in the Department of Cognitive Neuropsychology, Tilburg University, the Netherlands, and
- in my household, but many colleagues' households as well."

\section{How scientist-parents' pandemic experiences differed from those of their colleagues without children is also underscored in the responses.}

"I got a lot of e-mails from single/non-parent colleagues saying how nice the pandemic is and that we can finally concentrate on research (which was not at all my case, due to my son)."

"Most of the childless researchers were happy to do 'home office'; it was more peaceful without transport time to work. Doing home office, my research, my lectures online, with two children, wasn't easy."

"I think the only researchers who have benefited from COVID-19 are those who don't teach, don't have children, and don't have service roles. The workload for the rest of us has been enormous."

"Time and stress related to public transport disappeared."

"I have been more capable of focussing on the writing of my article due to fewer other activities and the lack of commuting."

is a former project manager at the Young Academy of Europe. Katalin Solymosi is an assistant professor in the Department of Plant Anatomy, ELTE Eötvös Loránd University, Budapest, Hungary, a board member of the Young Academy of Europe and co-chair of the Hungarian Young Academy. Mangala Srinivas is a professor of cell biology and immunology at Wageningen University and Research, the Netherlands, chief science officer at Cenya Imaging in Amsterdam and outgoing chair of the Young Academy of Europe.

1. Nature 562, S49-S51 (2018).

2. Castellacci, F. \& Viñas-Bardolet, C. Stud. Higher Educ. https://doi.org/10.1080/03075079.2019.1711041 (2020).

3. Husby, A. \& Modinos, G. Nature 580, 185 (2020)..

4. Yan, W. Science https://doi.org/10.1126/science.caredit. abc1291 (2020).

5. Nature 591, 489-491 (2021)

6. Langin, K. Science 371, 660 (2021).

7. UN Women. Whose Time to Care? Unpaid Care and Domestic Work During COVID-19. (UN Women, 2020).

8. Gewin, V. Nature 583, 867-869 (2020).

9. Larivière, V., Ni, C., Gingras, Y., Cronin, B. \& Sugimoto, C. R. Nature 504, 211-213 (2013).

10. Wingfield, A. H. Science 369, 351 (2020).

11. Dworkin, J. D. et al. Nature Neurosci. 23, 918-926 (2020).

12. Holman, L., Stuart-Fox, D. \& Hauser, C. E. PLoS Biol. 16, e2004956 (2018) 